СД-36.

\title{
ОПРЕДЕЛЕНИЕ ТИОЦИАНАТОВ И СВОБОДНЫХ, СЛАБОКИСЛОТНЫХ ДИССОЦИИРУЮЩИХ, ОБЩИХ ЦИАНИДОВ В ВОДНЫХ ОБЪЕКТАХ ФОТОМЕТРИЧЕСКИМ МЕТОДОМ С ПРИМЕНЕНИЕМ ПРОТОЧНОГО АНАЛИЗАТОРА «SKALAR SAN++»
}

Савватеева Т.А., Матасова Е.П., Полежаева И.В., Свиренко И.В.

Исследовательский центр АО «Полюс Красноярск», г. Красноярск PolezhaevaIV@polyus.com

DOI: 10.26902/ASFE-11_129

Анализатор автоматический проточный «Skalar San++» c фотометрическими детекторами позволяет автоматизировать стандартный фотометрический метод лабораторного анализа.

Принцип работы проточного анализатора «Skalar San++» заключаются в создании непрерывного сегментированного, при помощи воздушных пузырьков, потока анализируемых проб, который смешивается в реакционных сосудах с подаваемыми реагентами, подвергается (в зависимости от применяемого метода) нагреву, воздействию ультрафиолета, диализу и поступает в проточную кювету для фотоколориметрического измерения. Обработку и хранение данных, поступающих с каналов детектирования, осуществляют с помощью программного обеспечения «Flow Access».Анализатор «Skalar San++» оснащен двумя каналами детектирования для одновременного измерения массовой концентрации одного из видов цианидов и тиоцианатов.

Для гидрохимического анализа проб природных, сточных, сточных очищенных вод и технологических растворов разработали методику измерения массовой концентрации тиоцианатов и свободных, слабокислотных диссоциирующих (СКД) и общих цианидов фотометрическим методом с 4-пиридинкарбоновой и 1,3-диметилбарбитуровой кислотами с применением проточного анализатора «Skalar San++».

Измерения массовой концентрации каждого из определяемых видов цианидов в анализируемом растворе пробы проводят последовательно.Диапазоны определяемых концентраций: СКД, общих и свободных цианидов от 0,005 до 20 мг/дм³ ; тиоцианатов от 0,050

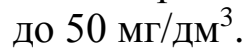

По предлагаемой методике не определяют цианиды, связанные в комплексы с кобальтом и органические цианиды.

\begin{tabular}{|c|c|c|}
\hline Диапазон измерений, мг/дм³ & $\begin{array}{c}\text { Показатель повторяемости, } \\
\sigma_{\mathrm{r}}, \mathrm{Mг} / \text { дм }^{3}\end{array}$ & 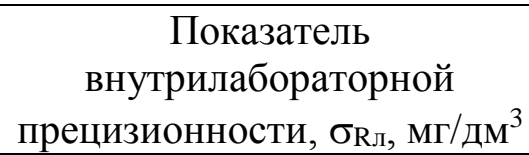 \\
\hline \multicolumn{3}{|c|}{ Цианиды } \\
\hline От 0,005 до 0,025 вкл. & $0,055 \cdot \mathrm{X}$ & $0,18 \cdot X$ \\
\hline св. 0,025 до 0,50 вкл. & $0,048 \cdot X$ & $0,13 \cdot X$ \\
\hline св. 0,50 до 20 вкл. & $0,021 \cdot \mathrm{X}$ & $0,075 \cdot X$ \\
\hline \multicolumn{3}{|c|}{ Тиоцианаты } \\
\hline От 0,050 до 0,50 вкл. & $0,067 \cdot X$ & $0,19 \cdot X$ \\
\hline св. 0,50 до 5,0 вкл. & $0,025 \cdot X$ & $0,12 \cdot \mathrm{X}$ \\
\hline св. 5,0 до 50 вкл. & $0,007 \cdot X$ & $0,063 \cdot X$ \\
\hline
\end{tabular}

